\title{
Hymenopteran Collective Foraging and Information Transfer about Resources 2012
}

\author{
F. A. L. Contrera, ${ }^{1}$ M. J. Couvillon, ${ }^{2}$ and J. C. Nieh $^{3}$ \\ ${ }^{1}$ Laboratório de Ecologia e Zoologia de Invertebrados, Instituto de Ciências Biológicas, Universidade Federal do Pará, \\ Rua Augusto Corrêa, No. 1, Campus Básico, Guamá 66075-110 Belém, PA, Brazil \\ ${ }^{2}$ Laboratory of Apiculture and Social Insects (LASI), School of Life Sciences, University of Sussex, Falmer, Brighton BN1 9QG, UK \\ ${ }^{3}$ Section of Ecology, Behavior, and Evolution, Division of Biological Sciences, University of California San Diego, \\ Mail Code 0116, 9500 Gilman Drive, La Jolla, CA 92093-0116, USA
}

Correspondence should be addressed to F. A. L. Contrera, felipe@ufpa.br

Received 9 July 2012; Accepted 9 July 2012

Copyright ( $) 2012$ F. A. L. Contrera et al. This is an open access article distributed under the Creative Commons Attribution License, which permits unrestricted use, distribution, and reproduction in any medium, provided the original work is properly cited.

\section{Introduction}

Foraging in social insects is a complex behavior, as it must balance the decisions made by individual foragers, which typically have limited information, against overall colony needs and the unpredictability of a changing environment. Even solitary insects must deal with the changing spatial and temporal availability of resources. Thus, social and solitary insects have evolved different foraging strategies, some of them studied in this special volume. The studies are divided in three sections: (1) the role of different types of information on nestmate activation during foraging (2) the role of recruitment and interference competition on foraging, and (3) the role of bee behaviors relevant for effective pollination.

\section{Information-Based Activation of Nestmates}

Social insect colonies can activate their constituents based upon new information during foraging. In this special issue, two papers, respectively, examine how this activation works for information about food competition and information about a profitable nectar source.

Within the same species, different colonies can compete for the same food sources. In their study on the effects of interference food competition in the ant, Lasius niger, Fourcassié and colleagues placed a conspecific competitor (an invader) from an alien colony in a foraging arena being exploited by a resident colony. Although the resident colony did not defensively recruit to the invaded foraging site, they responded locally. Resident foragers attacked the alien forager, and the number of resident foragers significantly increased through local recruitment to the vicinity of fights. The residents therefore responded locally, but the colony did not respond at a larger spatial scale to the presence of a competitor.

However, social insect colonies can also mobilize their efforts on a larger spatial scale. For example, they can mobilize nestmates to explore their environment for food and convey a range of information, from the simple existence of food (bumble bees [1]) to its presence and location (honey bees [2]). In their study on wasps, Polybia occidentalis, Schueller and Jeanne demonstrate that experienced foragers trained to a feeder could activate foraging for a food source and attract feeder-naïve nestmates (newcomers) to a feeder based upon its scent. These newcomers preferred visiting a feeder with the same scent as that brought back by experienced foragers over a feeder with a different scent. However, experienced foragers did not communicate food source location because newcomers did not significantly prefer the location visited by experienced foragers. This demonstrates that $P$. occidentalis, like bumble bees [3], can be activated to forage based upon food scent and follow an individual-based search strategy, not a group foraging strategy in which food location is also communicated. 


\section{Foraging Activity Regulation}

The seasonal changes in the environment, as well as the presence of invasive species, are factors known to influence the foraging behavior of social insects $[4,5]$, which developed several strategies to deal with these constraints. The contributions in this section deepen our understanding of the role of environment and invasive species on the foraging regulation in two species of ants and in a bee species. In their paper, Gúzman-Mendoza and coauthors show that in high productivity environments, the niche breadth of the ant, Pogonomyrmex barbatus, increases when the resources diminish (dry season) and it decreases when the environmental conditions are better (rainy season). However, in naturally poorer environments, the niche breadth is similar in both seasons. Their results show that $P$. barbatus colonies have different strategies of foraging in different environments, as related to local productivity and seasonal influences.

In another study, Paris and Espadaler showed that the richness of foraging native ants and the time they spent foraging in forest fragments are negatively affected by the presence of the invasive ant, Lasius neglectus, and also that trunks in isolated trees may act as dispersal stepping stones for this species. Lastly, Nascimento and Nascimento showed that the stingless bee Melipona asilvai, a species from a semiarid region, experiences a strong decrease in the foraging activity and honey storage in the rainy season, suggesting a seasonal diapause in this species.

\section{Bee Behaviors Relevant for Effective Pollination}

A majority of our commercial crops are insect pollinated [68]. However, as we are now all increasingly aware, both wild [9-11] and managed [11, 12] pollinators are experiencing declines in some parts of the world. This situation has focused our attention, as demonstrated in the last two papers, on current and possible future players on the pollinator stage.

The Japanese hornfaced bee Osmia cornifrons Radoszkowski (Hymenoptera: Megachilidae) was introduced into the United States in 1977, specifically as a pollinator of rosaceous fruit crops like apples and pears. However, $O$. cornifrons remains a relatively unstudied species. McKinney and Park analyzed trends in daily activity and found that behaviors correlated with temperature, rain, and time of day. These data may be useful for management practices, particularly in finding ways to minimize the impact of pesticides and suggestions for when best to move bees into crop blooms.

Kleinert and Giannini take a broader perspective in their paper. By building a bee-plant interaction matrix, the authors evaluate the bee-plant interactions in different locations within Brazil. They find that Apis mellifera, an introduced species to Brazil, and Trigona spinipes, a native Brazilian stingless bee species, are the most generalist species. Additionally, both A. mellifera and T. spinipes are distributed widely, possess a broad diet niche, and contain high levels of individuals per colony.

\section{F. A. L. Contrera \\ M. J. Couvillon \\ J. C. Nieh}

\section{References}

[1] A. Dornhaus and L. Chittka, "Information flow and regulation of foraging activity in bumble bees (Bombus spp.)," Apidologie, vol. 35, no. 2, pp. 183-192, 2004.

[2] K. von Frisch, The Dance Language and Orientation of Bees, Belknap Press, Cambridge, Mass, USA, 1967.

[3] A. Dornhaus and L. Chittka, "Evolutionary origins of bee dances," Nature, vol. 401, no. 6748, p. 38, 1999.

[4] D. A. Holway, L. Lach, A. V. Suarez, N. D. Tsutsui, and T. J. Case, "The causes and consequences of ant invasions," Annual Review of Ecology and Systematics, vol. 33, pp. 181-233, 2002.

[5] D. W. Roubik, "Seasonality in colony food storage, brood production and adult survivorship: studies of Melipona in tropical forest (Hymenoptera: Apidae)," Journal of the Kansas Entomological Society, vol. 55, pp. 789-800, 1982.

[6] A. M. Klein, B. E. Vaissière, J. H. Cane et al., "Importance of pollinators in changing landscapes for world crops," Proceedings of the Royal Society B, vol. 274, no. 1608, pp. 303313, 2007.

[7] I. H. Williams, "Aspects of bee diversity and crop pollination in the European Union," in The Conservation of Bees, A. Matheson, S. L. Buchmann, C. O. O'Toole, P. Westrich, and H. Williams, Eds., pp. 63-80, Academic Press, New York, NY, USA, 1996.

[8] M. H. Allsopp, W. J. de Lange, and R. Veldtman, "Valuing insect pollination services with cost of replacement," PLoS ONE, vol. 3, no. 9, Article ID e3128, 2008.

[9] S. G. Potts, J. C. Biesmeijer, C. Kremen, P. Neumann, O. Schweiger, and W. E. Kunin, "Global pollinator declines: trends, impacts and drivers," Trends in Ecology and Evolution, vol. 25, no. 6, pp. 345-353, 2010.

[10] I. Steffan-Dewenter, S. G. Potts, L. Packer, and J. Ghazoul, "Pollinator diversity and crop pollination services are at risk," Trends in Ecology and Evolution, vol. 20, no. 12, pp. 651-653, 2005.

[11] S. Kluser, P. Neumann, M.-P. Chauzat, and J. S. Pettis, Global Honey Bee Colony Disorders and Other Threats to Insect Pollinators, UNEP, 2011.

[12] P. Neumann and N. L. Carreck, "Honey bee colony losses," Journal of Apicultural Research, vol. 49, no. 1, pp. 1-6, 2010. 

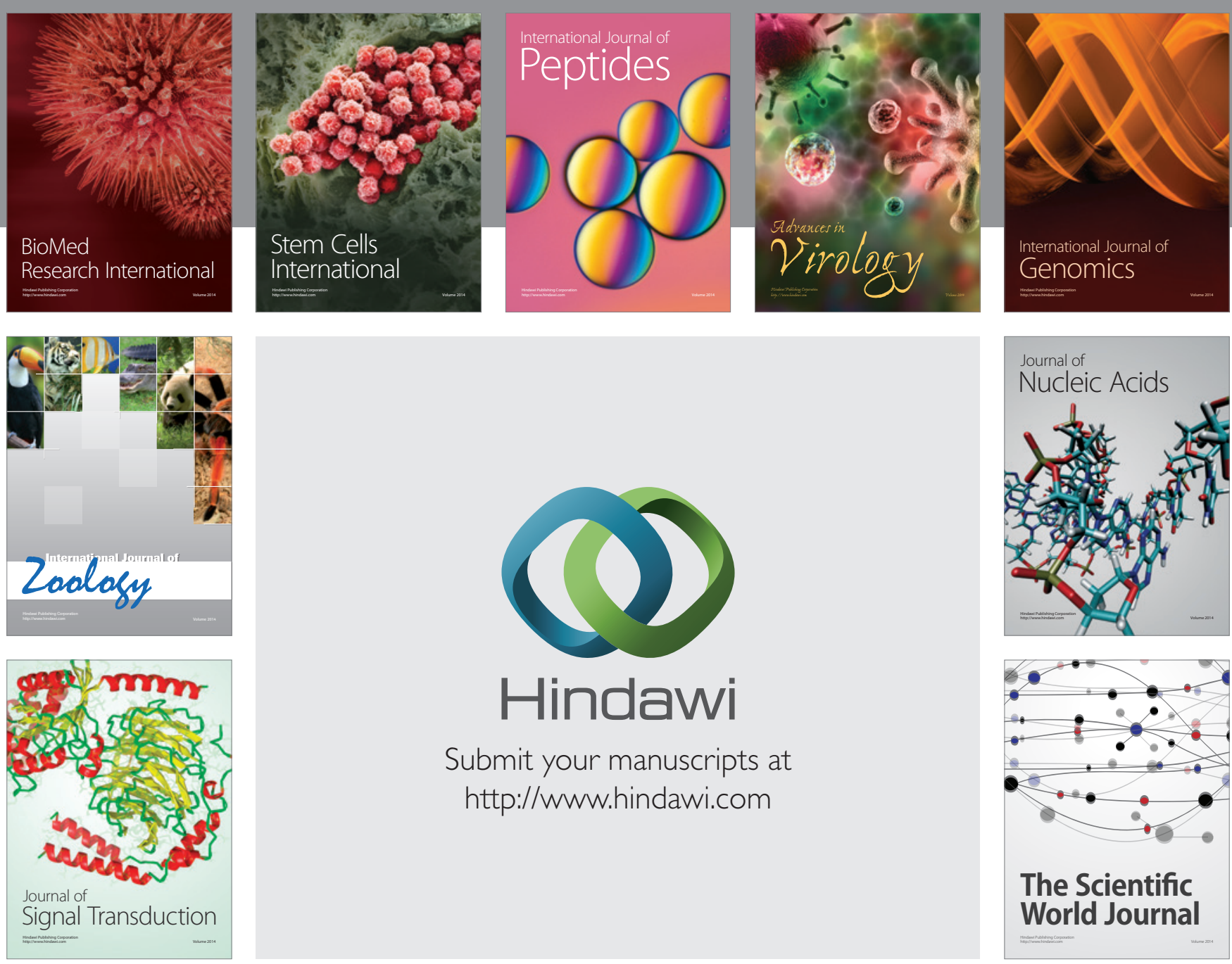

Submit your manuscripts at

http://www.hindawi.com
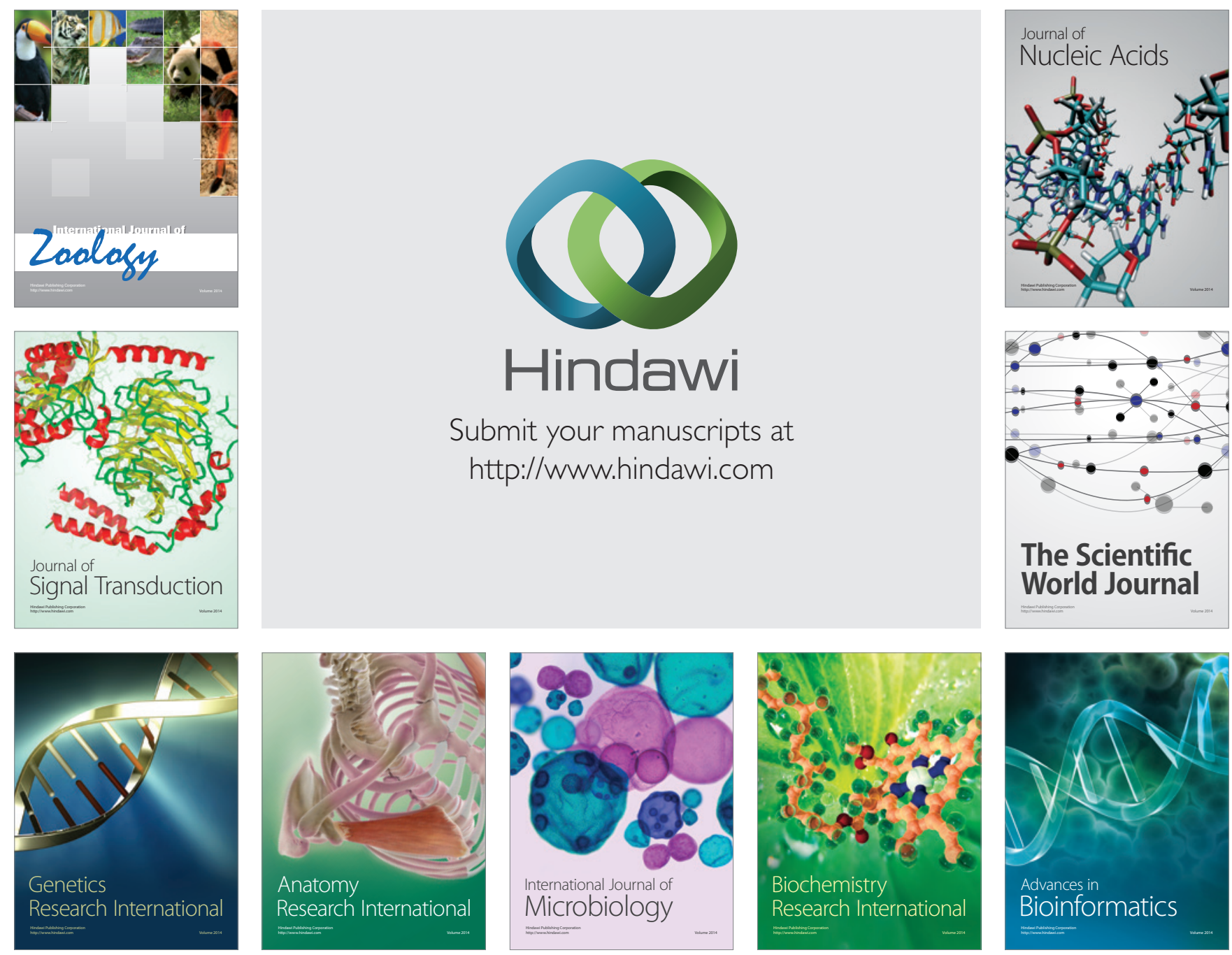

The Scientific World Journal
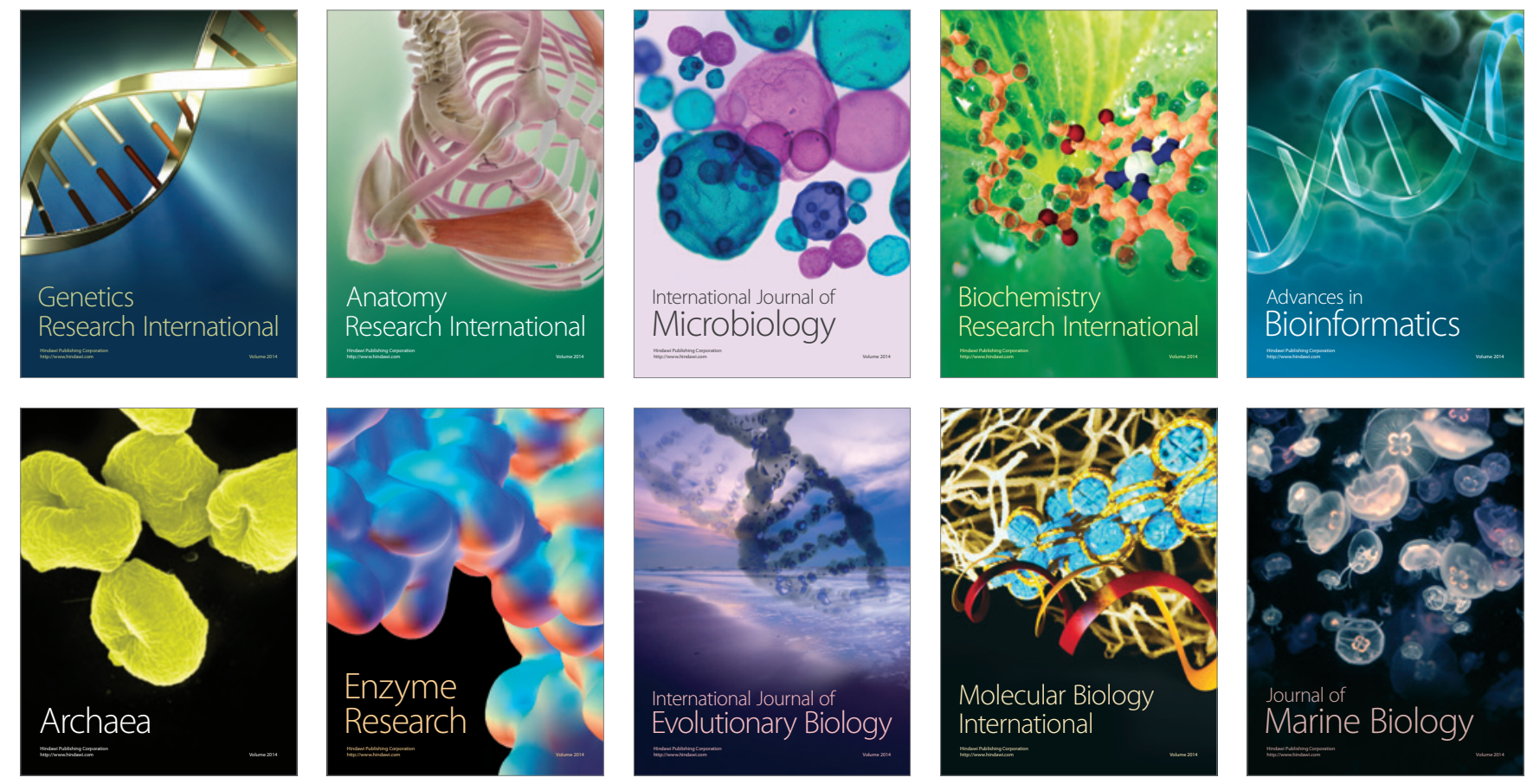